\title{
Valuing Exhaustible Resource Ownership: General Equilibrium Assets-Markets versus Partial Equilibrium
}

\author{
Johnson Kakeu \\ Department of Economics, Morehouse College, Atlanta, Georgia, USA \\ Email: justin.kakeu@morehouse.edu
}

How to cite this paper: Kakeu, J. (2018) Valuing Exhaustible Resource Ownership: General Equilibrium Assets-Markets versus Partial Equilibrium. Theoretical Economics Letters, 8, 844-853. https://doi.org/10.4236/tel.2018.85059

Received: November 30, 2017

Accepted: April 1, 2018

Published: April 4, 2018

Copyright $\odot 2018$ by author and Scientific Research Publishing Inc. This work is licensed under the Creative Commons Attribution International License (CC BY 4.0).

http://creativecommons.org/licenses/by/4.0/ (c) (i) Open Access

\begin{abstract}
This paper uses a general equilibrium assets-markets approach with arbitrageurs for valuing mineral resource deposit ownership. The results are contrasted with those delivered by a partial equilibrium approach. We show that in a general equilibrium assets-markets approach, arbitrageurs' valuation of resource deposit rights commands a discount factor that adjusts not only for the time depreciation but also for changes in the resource stock size over time. A general equilibrium assets-markets approach with arbitrageurs leads to a more conservative management of exhaustible natural resources than a partial equilibrium approach does.
\end{abstract}

\section{Keywords}

Conservation Finance, Arbitrageurs, General Equilibrium in Assets Markets, Partial Equilibrium, Mineral Rights Ownership, Capital Markets, Resource Conservation

\section{Introduction}

The main idea of this paper is to compare the implications of a general equilibrium (assets markets) model approach with that of a partial equilibrium (flow markets) model approach in valuing exhaustible natural resources.

A common approach used to address exhaustible resource problems is to rely on a partial equilibrium analysis. The given economy-wide interest rate is assumed to be exogenous in partial equilibrium, which implies decisions to hold mineral rights ownerships are modeled in isolation to the other non-resource assets markets. It is a one-way relationship in the sense that decisions to hold exhaustible resource ownerships do not affect the exogenous rate of interest, 
which is taken as given. In the [1] model, for instance, the rate of interest is taken as given to the resource markets by all other agents in the economy. This subtle assumption is rarely questioned. However, it is hard to believe that the interest rate is moving independently of the resource markets [2] [3] [4]. Partial equilibrium models may miss important interactions and feedbacks among various markets. The partial equilibrium approach tends to neglect the movement of factors of production across sectors. Therefore, there is no need to neglect a general equilibrium approach in which allocation of both mineral rights and ownership rights and conventional assets endogenously determine returns in capital markets.

No asset market exists in isolation. When an asset price in the market changes, this could cause a change in other asset prices. Therefore, it is worthwhile having a broad understanding of the financial markets and how each asset can impact another in order to trade accurately. The same arbitrageurs often invest across markets, and when returns change significantly in one asset market, arbitrageurs should expect similar tendencies to be happening in other markets as well. If the economy's capital stock is efficiently allocated, then all marginal returns on asset ownerships across sectors traded in capital markets should be equalized. The role of capital markets is to allow capital to flow freely to the activity that provides the highest net gain. A general equilibrium model with arbitrageurs allows an interaction among markets by enabling capital to be withdrawn from less profitable activities and reinvested to more profitable activities.

In a general equilibrium model with arbitrageurs, there is more flexibility and interactions across all ownership rights in all sectors due to the speculative role of arbitrageurs in financial markets ${ }^{2}$. Wealth may be owned in form of mineral rights ownership (mines, oilfields etc.). For an arbitrageur operating in capital markets, mineral rights ownership represents physical assets which can be used by arbitrageurs for financial speculations ${ }^{3}$. When arbitrageurs have the desired mix of assets of various types in their portfolios, they are in a situation of portfolio equilibrium.

Our work can be related to the broad literature that contrasts general equilibrium and partial equilibrium effects in analyzing economic decisions (see for instance [2] [3] [4] [8] [9] [10] [11]). For instance in the green paradox literature, [3] analyzes the impact of a future carbon tax on the negative externality generated by a fossil-fuel by using a trade model that accounts for resource windfalls, production and consumption. In their general equilibrium trade model setting, the future carbon tax changes factor prices and the interest rate. They found that, under certain circumstances, a general equilibrium might moderate or reinforce future carbon tax policy's partial equilibrium effects. Their model,

${ }^{1}$ This is also known as the knock-on effect.

${ }^{2}$ See for instance the empirical paper by [5].

${ }^{3}$ It can be assumed that ownership of the firm's capital stock is equivalent to ownership of the firm [6] [7]. 
however, do not explicitly account for the exhaustibility character of the fossil-fuel. Along the same lines, [9] shows that under plausible conditions a partial equilibrium model would overstate the magnitude of carbon leakage. [4] analyzes some empirical issues related to the estimates of the pollution haven effect in the trade and environment literature and argues that a partial equilibrium models may not carry over to a general equilibrium setting. In the public finance literature, [8] shows that in a general equilibrium, a tax that shifts capital or labor out of any one jurisdiction will raise the supply of capital or labor to other jurisdictions, lowering the return to capital or labor elsewhere.

This paper uses a general equilibrium assets-markets approach with arbitrageurs for valuing mineral resource deposit ownership. The results are contrasted with those delivered by a partial equilibrium approach. We show that in a general equilibrium assets-markets approach, arbitrageurs' valuation of resource deposit rights commands a discount factor that adjusts not only for the time depreciation but also for changes in the resource stock size over time. A general equilibrium assets-markets approach with arbitrageurs leads to a more conservative management of exhaustible natural resources than a partial equilibrium approach does.

This paper proceeds as follows. In Section 2, we present the valuation of mineral resource deposit ownership in a general equilibrium model with arbitrageurs. In Section 3, we compare a general equilibrium model with the [1] partial equilibrium model. We discuss a sense in which the [1] rule can be interpreted as a myopic valuation from a general equilibrium perspective. In Section 4, we compare general equilibrium and partial equilibrium valuation from a resource conservation perspective. The last section displays concluding comments.

\section{Valuing Mineral Rights in a General Equilibrium Assets-Markets Approach with Arbitrageurs}

In this paper, the general equilibrium model refers to assets markets where representative arbitrageurs can hold wealth in the form of conventional financial assets (say bonds) or in the form of exhaustible natural resource deposits. It is assumed that arbitrageurs are fully informed on the state of evolution of the natural resource stock size while making managing their portfolio. In other words, information on fundamentals of the economy including the resource stock size is incorporated in arbitrage trading activities. There is no uncertainty. The general pricing equilibrium is endogenously determined by the absence of arbitrage opportunities in assets markets [12]-[17]. More formally, suppose that assets markets consist of an exhaustible resource stock, denoted by $X$, and a conventional asset, denoted by $B^{4}$. The stock of resource is assumed to be a homogenous resource deposit ${ }^{5}$. The size of the initial endowment of the resource stock is denoted by $X_{0}>0$, and the remaining resource stock size at time $t$ is

${ }^{4} \mathrm{~A}$ conventional assets such as a bond or a capital good.

${ }^{5}$ That is, the costs of extraction of a unit from a deposit do not depend on the amount previously extracted. A similar assumption is made by [1]. 
denoted by $X(t)$.

Let us denote by $V(t)$ the stock market value of the resource deposit ownership in a general equilibrium of assets markets, in dollars, of a remaining known homogeneous resource stock $X(t)$ at time $t$. Denote by $B(t)$ the stock market value of the conventional asset at time $t$.

A general equilibrium assets-market approach with arbitrageurs allows a feedback by enabling capital to be withdrawn from less profitable activities and reinvested to more profitable activities ${ }^{7}$. In a general equilibrium assets-market approach with arbitrageurs, all sectors should strike the same financial rate of return. For arbitrageurs to include a resource deposit in their portfolio, the rate of change in the value of the resource deposition must equal the general equilibrium rate of return that prevails in all markets for capital assets. In the general equilibrium rate, the rate of return on mineral rights ownership $\dot{V}_{g e}(t) / V_{g e}(t)$ and the rate of return on other ownership categories $\dot{B}(t) / B(t)$ should be equalized $^{8}$. That is:

$$
\frac{\dot{V}_{g e}(t)}{V_{g e}(t)}=\frac{\dot{B}(t)}{B(t)}=\underbrace{r(X(t), B(t))}_{\text {General equilibrium Rate of Return }}
$$

where $r(X(t), B(t))$ is the general equilibrium rate of return on assets in assets markets with arbitrageurs. The absence of arbitrage opportunities is sufficient for the existence of a general equilibrium in well functioning and competitive financial markets [12]-[17]. The general equilibrium rate of return that emerges from arbitrage across all assets markets, $r(X(t), B(t))$ depends on the general asset structure of the economy.

This condition can be thought of as the law of one price in a general asset market equilibrium setting 9 .

Integrating both sides of Equation (1) leads to

$$
V_{g e}(t)=V_{0} \mathrm{e}^{\int_{0}^{t} r(X(\tau), B(\tau)) \mathrm{d} \tau} .
$$

In capital markets, the value of a capital stock is the product of the price of installed capital and the quantity of capital [6] [7]. Exhaustible resources deposits are a form of capital. Therefore, the worth of a resource deposit right in a general equilibrium in assets markets is obtained by multiplying the size of the resource deposit by the shadow value of the marginal unit of the resource in the ground. Let us denote by $\lambda_{g e}(t)$ the shadow price of the resource at time $t$ in a general equilibrium of assets markets. Therefore the market value of the resource stock in capital markets is given by the product of the shadow price of the resource

\footnotetext{
${ }^{6}$ Say a stock of oil in the ground.

${ }^{7}$ It is assumed that mineral rights ownership can be easily transferred in monetary value whenever possible.

${ }^{8}$ According to the seminal paper by [18], ownership is governed only by the preference of arbitrageurs to more or less gains.

${ }^{9}$ In other words, if the law of one price holds, then there is no ambiguity about the time t return on any marketable asset at any time $t$.
} 
$\lambda(t)$ and the remaining resource stock size $X(t)^{10}$ :

$$
V_{p e}(t)=\lambda_{p e}(t) X(t) .
$$

Substituting Equation (3) into Equation (2), the following valuation rule is obtained

$$
\underbrace{\lambda_{g e}(t)}_{\text {General equilibrium shadow price }}=\underbrace{\lambda_{0}}_{\text {Initial value }} \underbrace{\left[\frac{X_{0}}{X(t)}\right]}_{\text {Size change scale }} \underbrace{\left[\mathrm{e}^{\int_{0}^{t} r(X(\tau), B(\tau)) \mathrm{d} \tau}\right]}_{\text {Time discounting }} .
$$

Equation (4) tells us that from a general equilibrium assets-market approach, the endogenous discount rate used by arbitrageurs for valuing exhaustible resource deposits rights $\left[\frac{X_{0}}{X(t)} \mathrm{e}^{\int_{0}^{t} r(X(\tau), B(\tau)) \mathrm{d} \tau}\right]$ adjusts not only for the time depreciation but also for changes in the resource size over time.

\section{General Equilibrium Assets-Market Approach versus Partial Equilibrium Approach}

In this section, we compare the features derived from partial equilibrium (flow markets) considerations with those derived from general equilibrium in assets markets.

\subsection{The [1] Partial Equilibrium Setting}

In the [1] model, the interest rate is assumed exogenous, that is, the interest rate is taken as given to the mining industry by the rest of the economy [22]. To clarify, let us denote by $\lambda_{\text {pe }}$, the shadow price-price net of marginal cost in-situ in the [1] [23] [24] partial equilibrium model of exhaustible resources. As shown by [1] [23] [24], in the partial equilibrium the shadow price, $\lambda_{p e}$, must rise at the exogenous rate of interest ${ }^{11}$,

$$
\begin{array}{r}
\lim _{t \rightarrow \infty} \lambda_{p e}(t) X(t)=0 \\
\frac{\dot{\lambda}_{p e}(t)}{\lambda_{p e}(t)}=\tilde{r}(t) .
\end{array}
$$

In other words, from the partial equilibrium approach, stocks of natural resources are like capital goods. The shadow price of the marginal unit of resource in situ at time $t$ is obtained as follows:

$$
\underbrace{\lambda_{p e}(t)}_{\text {Partial equilibrium shadow price }}=\underbrace{\lambda_{0}}_{\text {Initial value }}[\underbrace{\left[\mathrm{e}^{t_{0}^{t}} \tilde{r}(\tau) \mathrm{d} \tau\right]}_{\text {Time discounting }} .
$$

\footnotetext{
${ }^{10}$ Let us mention that a similar relation can also be derived in a standard partial equilibrium model of exhaustible resource extraction as in [19, p. 617], [20, p. 16], and [21, p. 154]. In this case, the value of the resource stock in partial equilibrium is $V_{p e}(t)=\lambda_{p e}(t) X(t)$, where $\lambda_{p e}(t)$ is the shadow value of the marginal unit of a (homogeneous) Hotelling resource in partial equilibrium model. ${ }^{11}$ In addition, the transversality condition should be satisfied. That is,
}

$$
\lim _{t \rightarrow \infty} \lambda_{p e}(t) X(t)=0
$$


With a partial equilibrium setting, the value of one unit of the in situ resource time $t$ is obtained by applying the same discounted cash flow technique used for valuing conventional assets whose size is fixed over time.

\subsection{The [1] Rule Viewed from the General Equilibrium in Assets Markets Setting}

It is instructive to shed light on how the [1] can be interpreted within the previous general equilibrium framework. In the [1] model, the rate of return on other ownership categories is driven by an exogenous rate of interest $\tilde{r}(t)$. In order to replicate partial equilibrium behavior within a general equilibrium assets-market approach, it is reasonable to assume that the time-discounting is the same in both models. In other words, the rate of interest which is taken as given to the mining industry in [1] rule by the general equilibrium assets-market approach with arbitrageurs. In other words,

$$
r(X(t), B(t))=\tilde{r}(t)
$$

It is worth noting that the only case where the valuation from a general equilibrium assets-market approach with arbitrageurs equals the valuation from a partial equilibrium approach

$$
\lambda_{g e}(t)=\lambda_{p e}(t)
$$

happens if and only if

$$
X(t)=X_{0} \text { at any time } t>0 .
$$

The implication (10) suggests that from a general equilibrium assets-market approach with arbitrageurs perspective, the [1] valuation might be seen as a myopic rule. The intuition is the following. Analyzed from a general equilibrium assets-market approach with arbitrageurs, there seems to be a rigidity in the way the basic [1] rule prices marginal units of the exhaustible resource. Indeed, under the [1] rule, the remaining size by itself does not affect directly the valuation of any marginal unit valued. There is a separability between the size of the remaining stock and the value of the marginal unit of resource, suggesting that any marginal unit can be viewed itself as an initial stock of resource. This is another way to express the homogeneity of the marginal resource valuation in the [1] model. In contrast, in the general equilibrium model with arbitrageurs, the valuation of marginal unit of resource is adjusted for the size of the remaining stock. In other words, from a general equilibrium assets-market approach with arbitrageurs, a homogenous cost resource stock can be viewed as having an infinite grade deposit with respect to the size of the remaining stock at the margin.

\section{Resource Conservation: General Equilibrium Assets Markets vs. Partial Equilibrium Flow Markets}

Comparing the valuation of exhaustible resources using the partial equilibrium Equation (7) and the valuation of exhaustible resources using a general equili- 
brium (4), it follows that

$$
\lambda_{g e}(t)=\left[\frac{X_{0}}{X(t)}\right] \lambda_{p e}(t)
$$

Since the resource size can only decrease over time ${ }^{12}$; that is $\frac{X(t)}{X_{0}}<1$, it follows that

$$
\underbrace{\lambda_{g e}(t)}_{\text {General equilibrium shadow price }}>\underbrace{\lambda_{p e}(t)}_{\text {Partial equilibrium shadow price }}
$$

An interesting implication of this result is that a general equilibrium assets-market approach with arbitrageurs leads to a more conservative utilization of exhaustible natural resources. The presence of arbitrageurs allows a more conserving resource economy. The management of exhaustible resources under a general equilibrium assets-market approach leads to a more conservative policy than that obtained from a partial equilibrium framework. In a general equilibrium assets-market approach, all markets are simultaneously modeled and interact with each other.

Furthermore, as shown by [19] [20] [21], in partial equilibrium model of exhaustible resource extraction ${ }^{13}$, the value of the remaining stock at time $t$ is given by $V_{p e}(X(t))=\int_{t}^{\infty} \mathrm{e}^{-\tilde{r}(\tau-t)} \lambda_{p e}(\tau) q(\tau) \mathrm{d} \tau=\lambda_{p e}(t) X(t)$, where $\lambda_{p e}(\tau)$ is the shadow price of the resource at time $\tau$ in partial equilibrium (which is equal the price assuming that the extraction cost is zero) and $q(\tau)$ is the quantity extracted at time $\tau$, and $X(t)$ is the size of the remaining resource stock at time $t$.

The relative change in value of the stock of the resource can be derived as (see [19] [20] [21]):

$$
\frac{\dot{V}_{p e}}{V_{p e}}=\tilde{r}-\frac{\lambda_{p e}(t) q(t)}{V_{p e}} .
$$

Therefore taking into account Equation (8) and comparing Equation (13) with Equation (1) leads to

$$
\frac{\dot{V}_{p e}}{V_{p e}}<\frac{\dot{V}_{g e}}{V_{g e}},
$$

which implies

$$
V_{g e}(t)>V_{p e}(t) .
$$

This result tells us that the value of exhaustible resources deposits analyzed from a general equilibrium assets-market approach with arbitrageurs is greater than the value of exhaustible resources deposits analyzed from a partial equilibrium model. The resource owner in partial equilibrium does not internalize the effect of the resource size change on the rate of interest, which is taken as given.

\footnotetext{
${ }^{12}$ We have assumed a fixed stock of the homogenous exhaustible resource and no discoveries.

${ }^{13}$ The resource can be seen as a single large deposit, which is divided among many profit-maximizing competitive firms whose actions maximize both welfare and aggregate wealth.
} 
A direct implication is that in doing green accounting it is important to emphasize that the valuation depends on whether a partial equilibrium or a general equilibrium assets-market approach is used. An integrated and multi-sectorial asset market approach results in greater shadow price for mineral rights ownership and is likely to be more sustainable over the long term ${ }^{14}$.

\section{Concluding Remarks}

In this paper, we compare the valuation of exhaustible resources from both a general equilibrium assets-market approach with arbitrageurs and a standard partial equilibrium approach. It is shown that a correction term that explicitly accounts for the change in the resource size enters the discount factor used by arbitrageurs in a general equilibrium assets-market approach. Because of the presence of this term that adjusts for changes in the resource stock size over time, capital markets analyzed from a general equilibrium model with arbitrageurs' standpoint are more conservative than that obtained from a partial equilibrium approach in which the rate of interest is exogenously given. In some sense, our result echoes [22] who mentioned that assets markets are more farsighted than flow markets when it comes to resource conservation issues.

Our paper features a simple general model showing that integrated assets markets with informed arbitrageurs can play a better role in conserving natural resources than a partial equilibrium model approach does. This simple model can bring some insights on the link between capital market polices and long-term conservation of exhaustible natural resources, which is an important component of sustainable development. It shows that fully integrating accurate information on resource stock size into capital markets policy practices used by market participants would contribute to the promotion of a more resource conservative economy.

From a policy perspective, the conclusions derived from this paper provide a theoretical rationale behind the idea of conservation finance, a recently developed framework whose objective is to move resource conservation issues into mainstream assets markets [27]. Assets markets can play a better role in promoting resource conservation if relevant integrated reporting that incorporates environmental information and alongside financial information is provided to investors [27] [28] [29] [30] [31].

Our paper suffers from some limitations, one of which is inherent to general equilibrium approaches. As mentioned by [32], one of the well-known limitations of general equilibrium models is that it is assumed that nothing happens before the equilibrium is reached ${ }^{15}$. Another limitation of this research is that it does not account for issues such as asymmetric information, uncertainties in resource markets, technological change, and new discoveries. Future research will

\footnotetext{
${ }^{14}$ Exhaustible resources and conservation issues are at the top of the sustainable development agenda [25] [26].

${ }^{15}$ The general equilibrium approach is better suited for addressing long-term questions [32]. Needless to mention resource conservation is a long-term issue.
} 
incorporate these features.

\section{References}

[1] Hotelling, H. (1931) The Economics of Exhaustible Resources. Journal of Political Economy, 39, 137-175. https://doi.org/10.1086/254195

[2] Geldrop, J. and Withagen, C. (1993) General Equilibrium and International Trade with Exhaustible Resources. Journal of International Economics, 34, 341-357. https://doi.org/10.1016/0022-1996(93)90054-2

[3] Meijden, G., Ploeg, F. and Withagen, C. (2015) International Capital Markets, Oil Producers and the Green Paradox. European Economic Review, 76, 275-297. https://doi.org/10.1016/j.euroecorev.2015.03.004

[4] Karp, L. (2011) The Environment and Trade. Annual Review of Resource Economics, 3, 397-417. https://doi.org/10.1146/annurev-resource-083110-115949

[5] Caselli, F. and Feyrer, J. (2007) The Marginal Product of Capital. The Quarterly Journal of Economics, 122, 535-568. https://doi.org/10.1162/qjec.122.2.535

[6] Hall, R. (2001) The Stock Market and Capital Accumulation. American Economic Review, 91, 1185-1202. https://doi.org/10.1257/aer.91.5.1185

[7] Merton, R. (1973) An Intertemporal Capital Asset Pricing Model. Econometrica, 41, 867-887. https://doi.org/10.2307/1913811

[8] Bradford, D. (1978) Factor Prices May Be Constant But Factor Returns Are Not. Economics Letters, 1, 199-203. http://EconPapers.repec.org/RePEc:eee:ecolet:v:1:y:1978:i:3:p:199-203 https://doi.org/10.1016/0165-1765(78)90024-1

[9] Karp, L. (2013) The Income and Production Effects of Leakage. University of California, Berkeley.

[10] Shortle, J. and Willett, K. (1986) Incidence of Water Pollution Control Costs: Partial vs. General Equilibrium Computations. Growth Change, 17, 2. https://doi.org/10.1111/j.1468-2257.1986.tb00051.x

[11] Dumas, B. (1993) Partial vs. General-Equilibrium Models of the International Capital Market. Working Paper No. 4446. National Bureau of Economic Research, Cambridge, MA. https://doi.org/10.3386/w4446

[12] Werner, J. (1987) Arbitrage and the Existence of Competitive Equilibrium. Econometrica, 55, 1403-1418. https://doi.org/10.2307/1913563

[13] Le Van, C. and Ba Minh, N. (2007) No-Arbitrage Condition and Existence of Equilibrium with Dividends. Journal of Mathematical Economics, 43, 135-152. https://doi.org/10.1016/j.jmateco.2006.05.010

[14] Bosi, S., Fontaine, P. and Le Van, C. (2016) Interest Rates Parity and No Arbitrage as Equivalent Equilibrium Conditions in the International Financial Assets and Goods Markets. Mathematical Social Sciences, 82, 26-36. https://doi.org/10.1016/j.mathsocsci.2016.04.002

[15] Chichilnisky, G. (1995) Limited Arbitrage is Necessary and Sufficient for the Existence of a Competitive Equilibrium with or without Short Sales. Economic Theory, 5, 79-108. https://doi.org/10.1007/BF01213646

[16] Ross, S.A. (1976) The Arbitrage Theory of Capital Asset Pricing. Journal of Economic Theory, 13, 341-360. https://doi.org/10.1016/0022-0531(76)90046-6

[17] Varela, O. (2012) Arbitrage in General Equilibrium. Modern Economy, 3, 396-401. https://doi.org/10.4236/me.2012.34051 
[18] Modigliani, F. and Miller, H. (1958) The Cost of Capital, Corporation Finance and the Theory of Investment. The American Economic Review, 48, 261-297.

[19] Hamilton, K. and Hartwick, J. (2005) Investing Exhaustible Resource Rents and the Path of Consumption. The Canadian Journal of Economics/Revue canadienne d Economique, 38, 615-621. https://doi.org/10.1111/j.0008-4085.2005.00295.x

[20] Farzin, Y. (2004) Is an Exhaustible Resource Economy Sustainable? Review of Development Economics, 8, 33-46. https://doi.org/10.1111/j.1467-9361.2004.00218.x

[21] Dasgupta, H. and Heal, G. (1979) Economic Theory and Exhaustible Resources. James Nisbet and Cambridge University Press, Cambridge.

[22] Solow, R. (1974) The Economics of Resources or the Resources of Economics. American Economic Review, 64, 1-14. https://doi.org/10.1057/9780230523210_13

[23] Dasgupta, P. and Heal, G. (1974) The Optimal Depletion of Exhaustible Resources. The Review of Economic Studies, 41, 3-28. https://doi.org/10.2307/2296369

[24] Stiglitz, J. (1974) Growth with Exhaustible Natural Resources: Efficient and Optimal Growth Paths. The Review of Economic Studies, 41, 123-137. https://doi.org/10.2307/2296377

[25] Shafieea, S, Topal, E. (2009) When Will Fossil Fuel Reserves be Diminished. Energy Policy, 37, 181-189. https://doi.org/10.1016/j.enpol.2008.08.016

[26] Shams, M. (1990) Towards an Effective Oil Conservation Policy. Energy Policy, 18, 443-448. https://doi.org/10.1016/0301-4215(90)90044-5

[27] Credit Suisse AG and McKinsey Center for Business and Environment (2016) Conservation Finance from Niche to Mainstream: The Building of an Institutional Asset Class. Credit Suisse AG and McKinsey Center for Business and Environment, Zurich and New York.

[28] Carney, M. (2015) Breaking the Tragedy of the Horizon-Climate Change and Financial Stability. Speech Given at Lloyd's of London.

[29] Carney, M. (2016) Resolving the Climate Paradox. Arthur Burns Memorial Lecture, Berlin.

[30] Krosinsky, C., Robins, N. and Viederman, S. (2011) Evolution in Sustainable Investing: Strategies, Funds and Though Leadership. Wiley, Hoboken, NJ.

[31] Kiernan, M. (2009) Investing in a Sustainable World: Why GREEN Is the New Color of Money on Wall Street. Amacom, New York.

[32] Borges, A. (1986) Applied General Equilibrium Models: An Assessment of Their Usefulness for Policy Analysis. OECD Journal: Economic Studies, 7, 289-311. 